\title{
PATRIMÔNIO CULTURAL EM PONTA GROSSA (PARANÁ, BRASIL): ARTICULAÇÕES POSSÍVEIS ENTRE MEMÓRIA, HISTÓRIA E TURISMO
}

\author{
CULTURAL PATRIMONY IN PONTA GROSSA (PARANÁ, BRASIL): \\ POSSIBLE ARTICULATIONS BETWEEN MEMORY, \\ HISTORY AND TOURISM
}

\author{
Márcia Maria Dropa* \\ Luiz Fernando de Souza** \\ Miguel Bahl*** \\ Rita de Cássia da Silva Oliveira ${ }^{* * * * *}$
}

\begin{abstract}
RESUMO
Preservar o Patrimônio Cultural e desenvolver a atividade turística podem parecer, num primeiro momento, ações advindas de concepções antagônicas, como foram um dia as concepções de progresso e preservação. Os discursos teóricos acerca do assunto crescem sensivelmente em busca de um ponto de equilíbrio, de forma que Turismo e Cultura possam conviver harmonicamente, evidenciando uma questão mais importante, que é a referência à identidade da comunidade vista como uma necessidade e não como um mero produto turístico. A ênfase deste trabalho é o Patrimônio Histórico Edificado, quer dizer, o patrimônio construído pela sociedade, por meio da acumulação de esforços, mostrando sua capacidade construtiva, através dos tempos. A busca do referencial histórico sobre os bens protegidos na cidade de Ponta Grossa encaminhou-se no sentido de buscar as produções históricas relativas à cidade. Outro instrumento utilizado na pesquisa foi a entrevista, além da busca pelas fontes iconográficas. Constatou-se que as construções podem ser fontes novas e inesgotáveis na elaboração de uma nova concepção histórica, que está em permanente evolução. Nesse contexto, o acervo do patrimônio cultural por intermédio do patrimônio edificado deve ser abordado além de seus valores históricos e artísticos, deve ser visto como produto de fabricação, apreendido por meio da memória do fazer. E para entender a amplitude hoje delegada ao Patrimônio Cultural Urbano, tem-se que conhecer a cidade e a memória histórica e afetiva, selecionada por seus habitantes. Pode ser que, de posse de um novo referencial, interdisciplinando-se, o profissional em turismo, o historiador e o planejador urbano encontrem um caminho mais efetivo nesse mundo simbólico do Patrimônio e do Turismo.
\end{abstract}

Palavras-chave: Cidade. Patrimônio Cultural. Patrimônio Edificado. Memória. Turismo.

\footnotetext{
"Professora da Universidade Estadual de Ponta Grossa (UEPG). Departamento de Turismo. Membro do Conselho do Patrimônio Cultural de Ponta Grossa. mdropa@gmail.com

*** Professor da Universidade Estadual de Ponta Grossa (UEPG). Departamento de Turismo. Coordenador do Colegiado de Curso de Turismo. luizfersouza@uol.com.br

**** Professor Universitário Classe Titular da Universidade Federal do Paraná (Curitiba) junto ao Curso de Graduaçao em Turismo e no Programa de Mestrado e Doutorado em Geografia.migbahl@ufpr.br

***** Pedagoga. Doutora em Educação. Professora do Mestrado e do Doutorado em Educação da UEPG. Pesquisadora Produtividade em Pesquisa do CNPq. Coordenadora da Universidade Aberta para a Terceira Idade. soliveira13@uol.com.br
} 


\begin{abstract}
Retaining Cultural Heritage and develop the tourism activity may seem, at first sight, antagonistic conceptions as they were once the concepts of progress and preservation. The theoretical discourses on this matter grow appreciably in search of an equilibrium point where the binomial Tourism and Culture can live in harmony, indicating a more important issue, which is the reference to the identity of the community viewed as a necessity and not as a mere product tour. The emphasis of this work is the Historic Monuments, or it means to the equity built by society, through the accumulation of efforts by showing their capacity building through the ages. The matter of historical reference on the protected property in the city of Ponta Grossa walked in seeking the historical production for the city. Another instrument used in the research were interviews, besides the search for iconographic sources. It was found that buildings can be new and inexhaustible sources in developing a new conception of history, which is constantly evolving. In this context, the collection of cultural heritage through the built heritage should be addressed in addition to its historical and artistic values, should be viewed as a product of manufacture, seized through the memory of doing. And to understand the extent, now delegated to the Urban Cultural Heritage, one has to know the city and the historical memory and affective, selected by their inhabitants. It may be that, in possession of a new reference, is an interdisciplinary, professional in tourism, the historian and urban planner, find a more effective way in this symbolic world of Heritage and Tourism.
\end{abstract}

Keywords: City, Cultural Heritage, Historic Monuments, Memory and Tourism.

\title{
Introdução
}

Ao entrar em contato pela primeira vez com o trabalho de Ulpiano Bezerra de Meneses, uma frase enunciada por esse professor chamou a atenção e ficou gravada na memória de um dos autores do presente texto: "Analisar a cidade é também analisar a imagem da cidade" (1984, p. 199).

Uma cidade deve ser vista como expressão da cultura de um povo. No espaço urbano as marcas da História ficam muito claras no traçado de suas ruas, na projeção de suas praças, na arquitetura de seus edifícios, no conjunto de seus quarteirões. Ao observar uma cidade e as pessoas, o que se vê é a expressão da cultura, de sua maneira de se organizar.

Isso significa que uma cidade ou um espaço urbano é um tipo de escrita, uma espécie de texto que se pode ler. Qualquer que tenha sido seu processo evolutivo, uma cidade guarda fragmentos que permitem sua leitura.

Toda cidade tem a marca da presença do homem, por meio de suas construções, seu modo de vida, sua maneira de adaptar velhos padrões a novas atitudes. Qualquer parte de um ambiente urbano, seja um quarteirão, uma praça, um edifício, possui um significado mais representativo do que somente seus valores materiais. São elementos que simbolizam a relação entre o lugar e seus habitantes.

Uma cidade, no entanto, sofre transformações; não é um bem imóvel, mas dinâmico, que constantemente se altera. E nesse processo de transformação, "as casas, os objetos arquitetônicos são as palavras que a História vai deixando na cidade" (LYRA, 1984, p. 16).

Muitas dessas casas ou dessas cidades são protegidas sob a alegação de que possuem um valor. Mas o que tem valor? Que tipo de valor? Delegam-se, então, valores estéticos e/ou históricos a determinados bens que merecem proteção. Porém, o que se pode verificar, mais especificamente em Ponta Grossa (Paraná, Brasil), é que inúmeras edificações foram destruídas no passado, como não tendo valor nem estético, nem histórico, e neste Século XXI lamenta-se a perda de incomparáveis patrimônios. 
Se uma cidade é feita de homens, com todas as relações sociais pertinentes ao convívio, pode-se até afirmar que ela seja um Patrimônio Cultural, isto é, um bem representativo dessa vida coletiva. E, sendo assim, é necessário protegê-la. Diante disso, outras indagações surgem, tais como: $\mathrm{O}$ que preservar? Por que preservar? Como preservar? É possível dizer que os sentidos da preservação só existem diante da ameaça de perda.

Só existe a preocupação de proteger alguma coisa se há risco de perdê-la [...]. Desaparecer ou permanecer são funções do tempo, só no decorrer é que as coisas ficam ou passam. A ação humana ambiciona intervir nesse processo, selecionando o que guardar e o que deixar de lado ou destruir [...]. Essa tendência de tornar presentes o passado e o futuro, garantindo a permanência de objetos e valores caros a uma cultura, parecem ser inerentes à sociedade [...]. (SILVA, 1996, p.165).

Quais os critérios, então, que devem nortear o que deve permanecer e o que deve desaparecer? É uma decisão, ou uma escolha? Sabe-se que, em épocas distintas, o que se pode destruir (tanto em ideias como em coisas) muda de lugar com o que se quer preservar. Assim, a decisão nem sempre é a mesma, e muito menos os objetos. O que permanece é o ato de escolher e de selecionar (SILVA, 1996). Nesse sentido, o presente artigo apresenta uma discussão sobre a articulação entre a preservação da memória enquanto elemento constitutivo da história e sua vertente na atividade turística, voltadas à questão da construção do Patrimônio Cultural representativo do município de Ponta Grossa.

\section{A preservação do Patrimônio Cultural}

No Brasil, a partir da criação do Serviço do Patrimônio Histórico e Artístico Nacional - SPHAN, em 1937, o Estado tomou para si a tarefa de selecionar, denominar e proteger o Patrimônio Cultural, até como garantia da construção de uma identidade nacional, ou com a intenção de "abrasileirar os brasileiros" (Mário de Andrade apud FENELON, 1992, p. 29). A expressão utilizada para designar os bens culturais passa a ser, então, Patrimônio Histórico e Artístico Nacional.

A preservação do patrimônio é um problema muitas vezes difícil de ser solucionado. Se for admitido que tudo é patrimônio, tudo deve ser conservado. Por isso, é preciso fazer uma crítica e interrogar-se sobre a conceituação de patrimônio. Não resta dúvida de que tudo pode ser considerado patrimônio, porém Monnet (1996, p. 228) destaca que

[...] o patrimônio só existe porque protegemos algo que denominamos assim. Designação e proteção vão juntas. Do fato mesmo de protegê-lo, o sacralizamos, isolando-o do destino habitual das coisas; por ser sacralizado ele deve ser protegido.

Atualmente, o conceito de patrimônio histórico vai sendo paulatinamente desvinculado da noção tradicional de consagrar bens que acentuavam apenas a presença do Estado, das instituições estabelecidas e das classes sociais dirigentes. Sendo assim, o termo ampliou-se para Patrimônio Cultural, e falar nele, é falar de valores. Como destaca Meneses (1984, p. 189), "é preciso, pois, sublinhar que os valores são sempre atribuídos, daí serem historicamente marcados". Para isso, designam-se quatro categorias de valores que podem operar na definição do significado cultural do bem: valores cognitivos (associados ao conhecimento), valores formais (funções estéticas), valores afetivos (relações subjetivas) e valores pragmáticos (de uso).

Ressalta-se, aqui, um foco de discussão que tem ocorrido frequentemente entre os especialistas, em relação ao patrimônio histórico e artístico e suas relações com o patrimônio cultural, patrimônio ambiental e bem cultural.

Entende-se por bens culturais toda a produção material e imaterial do homem, bem como o conjunto desses bens ${ }^{1}$, produzidos num processo social determinado. Destaca-se que os bens que compõem o patrimônio cultural não são "apenas signos que constituem discursos do presente com o passado [...] eles devem ser interpretados como signos novos, articulados em linguagem de hoje e constitutivos de práticas sociais atuais" (ARANTES, 1987, p. 53).

$\mathrm{O}$ assim chamado Patrimônio Cultural inclui tanto o Patrimônio Histórico como o Patrimônio

\footnotetext{
${ }^{1}$ Bens culturais: é todo o resultado da atividade humana, decorrente da convivência do homem na sociedade. E, ainda, segundo a Conferência Geral da ONU para a Educação, a Ciência e a Cultura (11/1968), a expressão bens culturais engloba não só os sítios e monumentos arquitetônicos, arqueológicos e históricos reconhecidos e protegidos por lei, mas os vestígios do passado não reconhecidos nem protegidos, assim como os sítios e monumentos recentes de importância artística e histórica. Cartas Patrimoniais. Cadernos de Documentos, IPHAN. Brasília, 1995.
} 
Natural. Ao se destacar a primeira expressão, entenda-se não apenas o Patrimônio Arquitetônico, mas também o Patrimônio Documental e Arquivístico, Bibliográfico, Hemerográfico, Iconográfico, Oral, Visual, Museológico, quer dizer, todo o conjunto de bens que atestam a História e a Cultura de uma determinada sociedade.

Sendo assim, entende-se por Patrimônio Cultural toda ação humana na prática da convivência em sociedade. Não há necessidade pura e simples de um reconhecimento oficial por meio do tombamento, para que determinado bem e/ou produção torne-se patrimônio. O patrimônio deve existir e ser referenciado como tal pela própria comunidade em que está inserido.

A ênfase deste artigo é o Patrimônio Histórico Edificado, quer dizer, o patrimônio construído como acumulação dos esforços que uma sociedade herda e que vem expressar o crescimento e desenvolvimento de sua capacidade construtiva, através do tempo. Deve-se permitir que o patrimônio arquitetônico sobreviva, que tenha e ganhe vida. Para que isso aconteça, deve-se levar em consideração, além de seus valores estéticos e históricos, sua capacidade de reciclagem, permitindo-lhe usos dinâmicos pela comunidade local e também pela atividade turística.

\section{A preservação do Patrimônio Cultural e sua dinâmica no município de Ponta Grossa}

Partindo da problemática da preservação do Patrimônio Histórico em Ponta Grossa, vários questionamentos surgiram: por que preservar o patrimônio da cidade? Qual a importância da preservação? Que análise histórica pode conter? Como encarar a complexa problemática da preservação e do desenvolvimento? E, principalmente, como articular a prática preservacionista com o desenvolvimento do turismo? Essas indagações surgem quando se percebe que possuímos uma herança intelectual que supõe um antagonismo entre o "moderno" e o "antigo". Ou, ainda, quando se defende a ideia de que se somente bens de valores monumentais devem ser preservados.

O resgate histórico dos prédios tombados em Ponta Grossa se fez necessário pela rapidez com que a cidade perdeu - e está perdendo, pela destruição o seu patrimônio edificado. Muitas vezes, essa des- truição foi justificada pelo discurso do progresso e da modernidade, e pela ocupação do espaço de formas diferenciadas.

O exercício de se pensar no equilíbrio entre a permanência e a mudança leva ao princípio de que a perda de muitos elementos, que na maioria das vezes são difíceis ou impossíveis de serem recriados, conduz ao desaparecimento de determinados referenciais, fazendo com que o cidadão não encontre mais seu lugar na cidade, não se reconheça no seu meio ambiente.

A necessidade de conservar os elementos que tornam as cidades mais humanas faz com que a preservação assuma um significado mais amplo. Ela é uma garantia de permanência do caráter das áreas e contribui para a compreensão do conjunto de elementos que as caracterizam, de suas tradições, instituições sociais, enfim, do que ali ocorre, ocorreu e ocorrerá.

Desta forma, a preservação não seria privilégio de alguns, de uma 'elite intelectual', mas sim um importante fator para a estabilidade da cidade e de seus habitantes (FONTES et al., 1986, p. 52).

Modificar essa situação de destruição do patrimônio na cidade terá início quando todos os setores da sociedade, sejam nas escolas, na imprensa, na Prefeitura e Câmara Municipal, nas associações culturais, entre outros, iniciarem uma ampla discussão para desmistificar a questão de que, para uma cidade crescer, se desenvolver, é preciso destruir o passado, a história, a memória e a identidade. O progresso e a preservação são conciliáveis, e a sociedade precisa compreender por que preserva. Sendo assim, acredita-se que o turismo planejado de forma sustentável, dentro dos princípios da conservação, pode e deve ser um grande aliado em todo o processo de preservação da memória, da identidade e dos referenciais arquitetônicos.

Considera-se que uma política eficaz para o Patrimônio Histórico-Cultural, que desenvolva o exercício da cidadania, deve englobar a ação do Poder Público e da sociedade civil como um todo, desenvolvendo três grandes áreas: a Educação $\mathrm{Pa}$ trimonial, a Preservação e a Atividade Turística. Entenda-se por Educação Patrimonial a utilização de museus, monumentos, arquivos, bibliotecas - os lugares da memória - no processo educativo, a fim de desenvolver a consciência de todos. Por intermédio 
da Educação Patrimonial, deve-se despertar em todos o senso de preservação da memória histórica, o consequente interesse pelo tema e o desenvolvimento do turismo, pois uma cidade "só será boa para o turista, quando for boa para sua própria população".

A preservação deve ser entendida como um direito do cidadão comum à cultura, à memória coletiva e ao passado histórico, formando uma dimensão fundamental da cidadania cultural. $O$ interesse original de um dos autores deste artigo sempre foi estudar a questão da preservação. De início, o objeto de trabalho versava sobre aspectos museológicos e sua representatividade, mas mudou-se de tema a partir da leitura do trabalho de Jeudy (1990, p. 13), que afirma: "O patrimônio, uma vez constituído, não é mais que um museu do social".

As dificuldades encontradas para trabalhar sobre esta vertente da preservação decorre, em parte, do fato de ser recente o ingresso de profissionais do turismo na área do Patrimônio Cultural, domínio que ainda é restrito à atuação de outros profissionais. Também se deve levar em consideração que a conceituação de bem cultural amplia-se sempre, e dependendo das forças políticas em voga, cada geração faz leituras diferenciadas do patrimônio. Por mais que ações voltadas à educação patrimonial e à educação turística reforcem a ideia da necessidade de preservação sustentável do patrimônio cultural, o que se pode observar é que essa forma de preservação ainda é distante da cultura de massa.

Assim, Nora (1993, p. 7) usa a expressão "aceleração da história" para caracterizar a situação em que o passado vai perdendo lugar para o presente eterno, trazendo a ameaça da perda da identidade. Segurar traços e vestígios é a forma de contrapor-se ao efeito desintegrador da rapidez contemporânea. Ponta Grossa é uma cidade histórica. É ambíguo e redundante fazer tal afirmação, mas ela é feita para relevar a necessidade preservacionista na cidade, para relembrar algo da literal destruição por que passou muito da memória da cidade e para sublinhar a história local em qualquer interferência preservacionista. Modernização ora planejada, ora injustificável, foi responsável pelo desaparecimento (criminoso) da Catedral do Bispado, da Cervejaria Adriática, da Casa do Bispo e também de várias residências. Diz-se criminoso porque algumas edificações foram demolidas durante a noite, para evitar-se quaisquer tipos de protestos.
Num determinado contexto (oportunidades e ameaças), Ponta Grossa conseguiu segurar alguns traços e vestígios de sua história urbana, quando a Coordenadoria do Patrimônio Cultural da Secretaria de Estado da Cultura, em 1990, tombou seis edificações. Destaca-se que se delegou ao Estado o papel de guardião de tal memória, principalmente devido à gravidade do processo de destruição pelo qual passava a cidade.

A busca do referencial histórico sobre os bens protegidos na cidade encaminhou-se no sentido de buscar, primeiramente, todas (não são muitas) as produções históricas relativas à cidade. A partir de então, os jornais do período foram outra fonte pesquisada. Fez-se referência à palavra fonte no singular porque o informativo do início do século, na cidade, resumia-se ao Jornal Diário dos Campos. No entanto, em relação à pesquisa realizada sobre os tombamentos, utilizou-se, além do Jornal Diário dos Campos, também o Jornal da Manhã para o período de 1990. Foi surpresa agradável encontrar, no acervo documental do Museu Campos Gerais, álbuns e revistas sobre o Estado e a cidade, destacando-se o Álbum do Paraná de 1920.

Outro instrumento utilizado na pesquisa foi a entrevista: foram entrevistados habitantes que possuíam lembranças sobre histórias relativas aos prédios preservados. Além disso, a busca pelas fontes iconográficas (que de início acreditava-se difícil) foi muito produtiva, referenciando-se até mesmo o costume frequente de fotografar a cidade. A utilização da memória iconográfica permitiu resgatar os principais momentos históricos dos bens preservados. No que diz respeito às plantas da cidade e dos prédios, as fontes iconográficas não foram encontradas. Algumas das fotos foram obtidas junto ao "Projeto de Preservação da Memória Histórica dos Campos Gerais"2, e outras junto a acervos particulares.

Os Processos de Tombamentos foram outra fonte utilizada. Como não foram encontrados em nenhum órgão da cidade, recorreu-se aos arquivos da Coordenadoria do Patrimônio Cultural do Paraná, em Curitiba.

\footnotetext{
2 Tal projeto foi desenvolvido pelo Departamento de História da Universidade Estadual de Ponta Grossa, durante dez anos. Além das fotos coletadas existem: documentação, entrevistas, fitas de vídeo de toda a região dos Campos Gerais do Paraná.
} 
A história dos tombamentos é interessante no sentido de que a preocupação de proteger só se manifestou na cidade quando os prédios foram ameaçados de demolição ou de descaracterização.

O ano de 1990 marcou a cidade com uma política de reestruturação do espaço urbano, em função de melhorias do transporte coletivo. Espaços ocupados anteriormente (como o caso da Rede Ferroviária) estavam ameaçados de uma retaliação mercantil, o que alteraria sensivelmente a imagem da cidade, inclusive com a demolição parcial dos prédios da Estação Ferroviária. Além disso, a Mansão Vila Hilda, que era a sede da Biblioteca Pública Municipal, seria totalmente camuflada, em função de uma tentativa de ampliação de seu espaço interno por uma utilização dita "moderna" e "racional".

De repente, "desmancharíamos com os pés o que fizeram com as mãos” (LEMOS, 1992, p. 216). Sendo assim, parte da população mobilizou-se e enfrentou a prefeitura na defesa desses bens. A primeira ameaça recaía sobre a Vila Hilda, que foi conservada por iniciativa de um grupo de artistas plásticos que conseguiu chamar a atenção para o tema e, com isso, mobilizar a opinião pública em defesa daquela casa. Fosse o que fosse, ela deveria ser preservada.

A partir daí, a preocupação girou em torno da defesa dos dois prédios das antigas estações ferroviárias. Novamente o grupo citado anteriormente mobilizou-se, juntamente com a UEPG e segmentos da sociedade, na defesa do complexo ferroviário.

A polêmica em torno desses prédios surgiu a partir do tombamento. O que fazer com o espaço? Em função do projeto municipal de alocar, naquele espaço, o terminal rodoviário urbano e o restante da área ser vendida a empresas particulares, o debate, e até um embate, teve início. Ocorreu, então, uma acirrada discussão pública entre a "permanência" e a "mudança".

Aproveitando o momento de discursos pela necessidade de preservação, novos tombamentos foram solicitados, entrando na lista de bens protegidos mais três edificações: o prédio da PROEX ${ }^{3}$, o do antigo Fórum ${ }^{4}$ e o do Colégio Estadual Regente Feijó.
Os prédios descritos a seguir são edificações tombadas no município de Ponta Grossa e compõem o quadro de bens protegidos pela legislação estadual. Em roteiros turísticos propostos na cidade, eles são geralmente visitados. São parte orgânica do passado e, à medida que se olha para eles, é possível estabelecer-se, por seu intermédio, uma relação com esse passado.

1 - Mansão Vila Hilda: construção da década de 1920, um dos últimos resquícios da arquitetura de habitação do início do século. Sua função atual é como sede da Secretaria Municipal de Cultura e Turismo. Tombada em 1990.

Figura 1- Mansão Vila Hilda

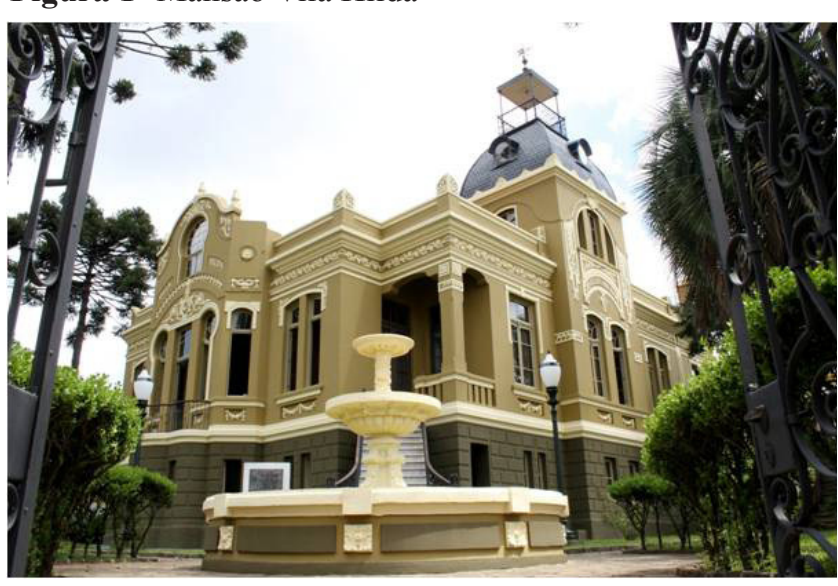

Fonte: SMCT- Ponta Grossa

2 - Prédio do antigo Fórum: também é uma construção da década de 1920, sendo o último registro da arquitetura oficial da cidade no período. O prédio abrigou o Museu Campos Gerais, gerenciado pela Universidade Estadual de Ponta Grossa. Hoje está desativado para ser restaurado. Tombado em 1990.

\footnotetext{
3 Pró-Reitoria de Extensão Universitária da Universidade Estadual de Ponta Grossa.

${ }^{4}$ Atual Museu dos Campos Gerais da Universidade Estadual de Ponta Grossa.
} 
Figura 2 - Antigo Prédio do Fórum

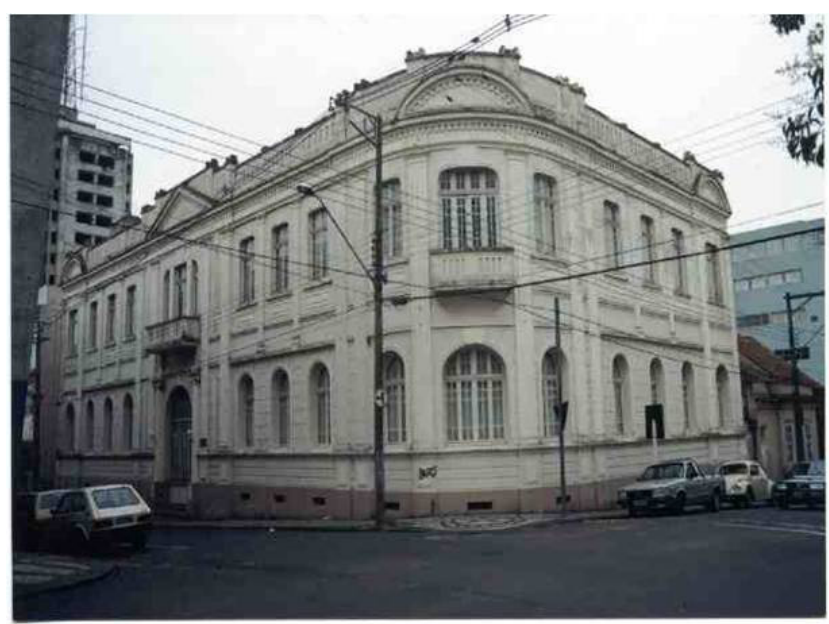

Fonte: SMCT- Ponta Grossa

3 - Prédio do Colégio Estadual Regente Feijó: construção do final da década de 1920, representa um período de descentralização estadual da educação. Apesar de ter sido interditado algumas vezes pela Defesa Civil, devido ao seu precário estado de conservação, esse prédio ainda abriga o Colégio Estadual Regente Feijó. Atualmente está restaurado. Tombado em 1990.

Figura 3 - Colégio Estadual Regente Feijó

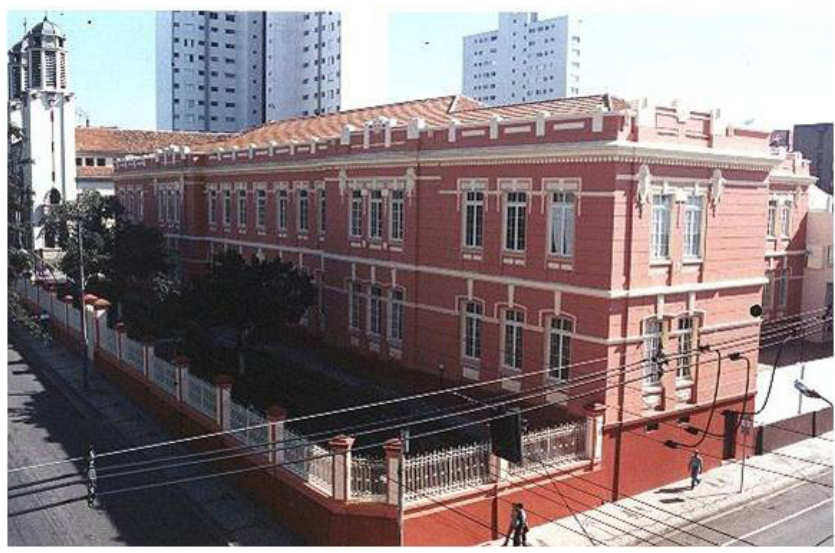

Fonte: SMCT- Ponta Grossa

4 - Edifício Guilherme Naumann (PROEX): é o exemplo da arquitetura funcional ligada ao comércio, sendo construído em 1907. Totalmente restaurado, é a sede da Pró-Reitoria de Extensão e Assuntos Culturais da Universidade Estadual de Ponta Grossa. Hoje é conhecido como prédio da PROEX. Tombado em 1900.
Figura 4 - Edifício Guilherme Naumann

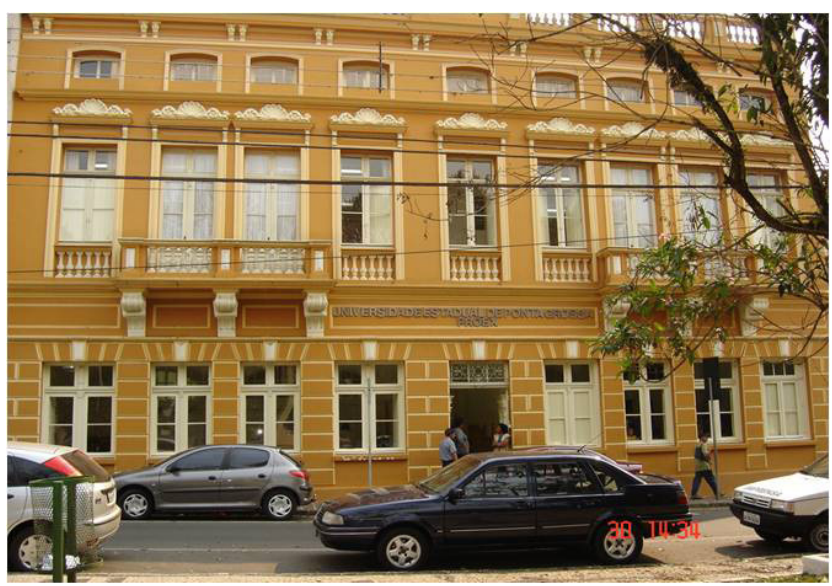

Fonte: SMCT- Ponta Grossa

5 - Complexo da Rede Ferroviária: são dois os prédios tombados em 1990. O primeiro, inaugurado em 1896, pertencia à Estrada de Ferro Paraná, sendo por isso conhecido até hoje como Estação Paraná. Atualmente é a sede da Casa da Memória. O segundo, a Estação São Paulo Rio Grande, foi inaugurado em 1900, é maior e possui um trabalho arquitetônico mais bem elaborado. Foi restaurado e é a atual sede da Biblioteca Pública Municipal Professor Bruno Enei. A antiga estação é hoje conhecida como Estação Saudade.

Figura 5 - Estação Paraná

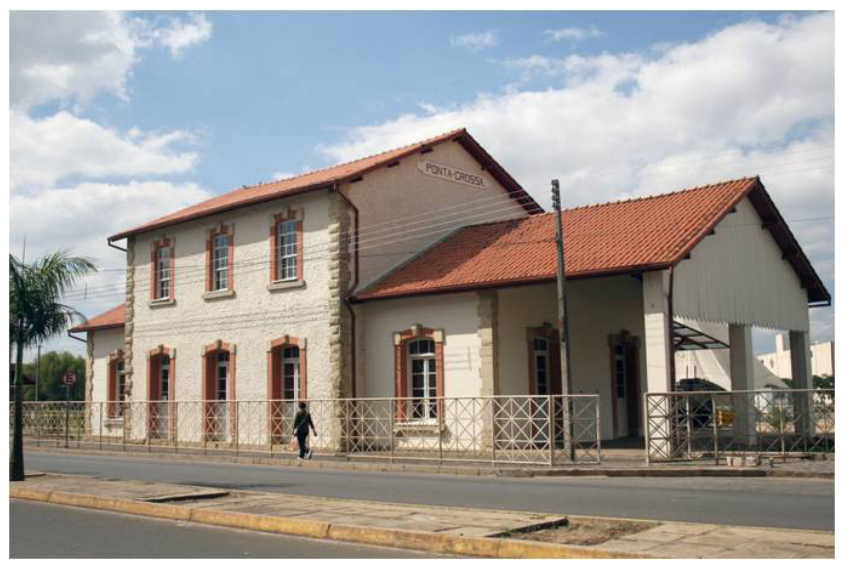

Fonte: SMCT- Ponta Grossa 
Figura 6 - Estação São Paulo-Rio Grande

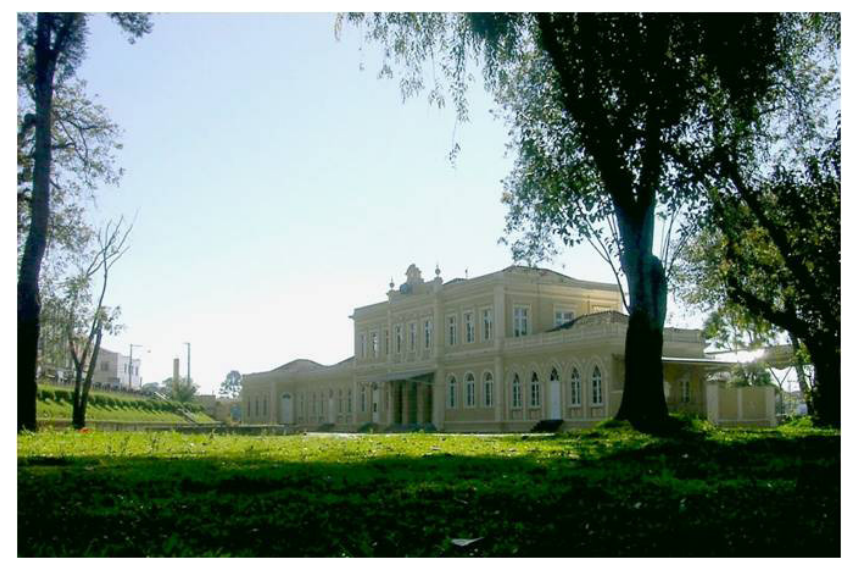

Fonte: UEPG- SMCT- SESI - Ponta Grossa

6 - Prédio do antigo Hospital 26 de Outubro: integra o conjunto de edifícios da Rede Ferroviária. Construído para ser um hospital, foi inaugurado em 25 de janeiro de 1931. No complexo do hospital foi construída uma capela com ornamentação expressiva nas paredes internas. Também são significativos os vitrais nela instalados em 1956, em comemoração ao cinquentenário da Cooperativa 26 de Outubro (Figuras 7 e 8$)$.

Figura 7 - Antigo Hospital 26 de Outubro

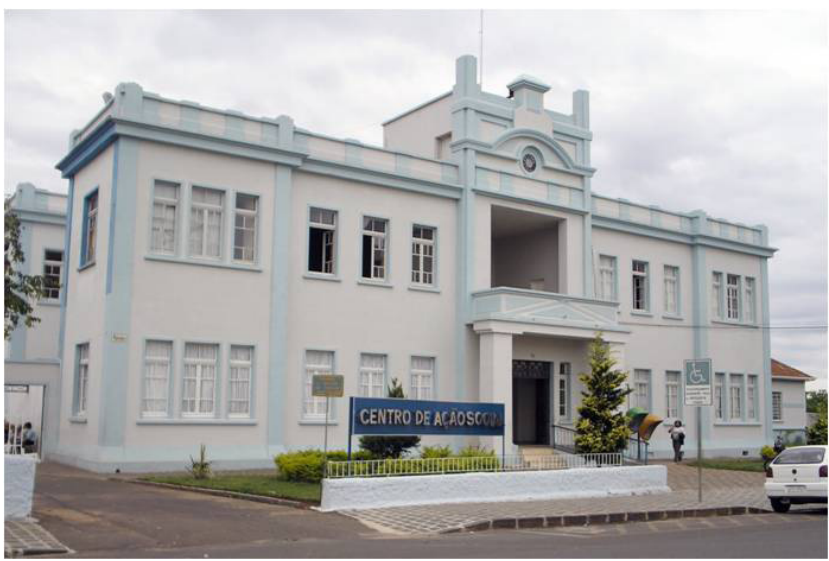

Fonte: SMCT- Ponta Grossa
Figura 8 - Capela São José - Antigo Hospital 26 de Outubro

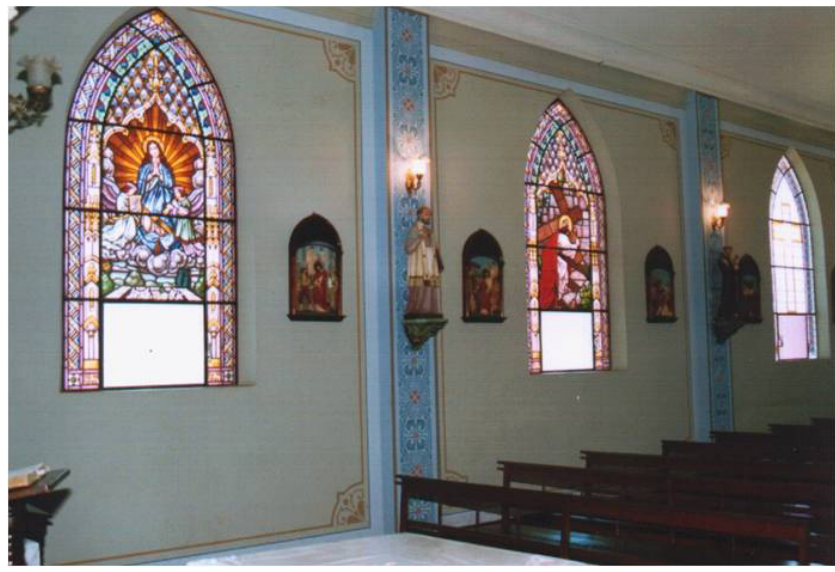

Fonte: SMCT- Ponta Grossa

7 - Capela Santa Bárbara do Pitangui: Primeira capela construída em Ponta Grossa, tem sua história ligada à presença dos jesuítas e ao movimento das tropas. A sesmaria do Pitangui foi doada aos padres jesuítas, que construíram no local uma pequena capela. Com a abertura do Caminho das Tropas, em 1731, o qual passava pelo local, os padres dedicaram a capela a Santa Bárbara.

Figura 9 Capela Santa Bárbara

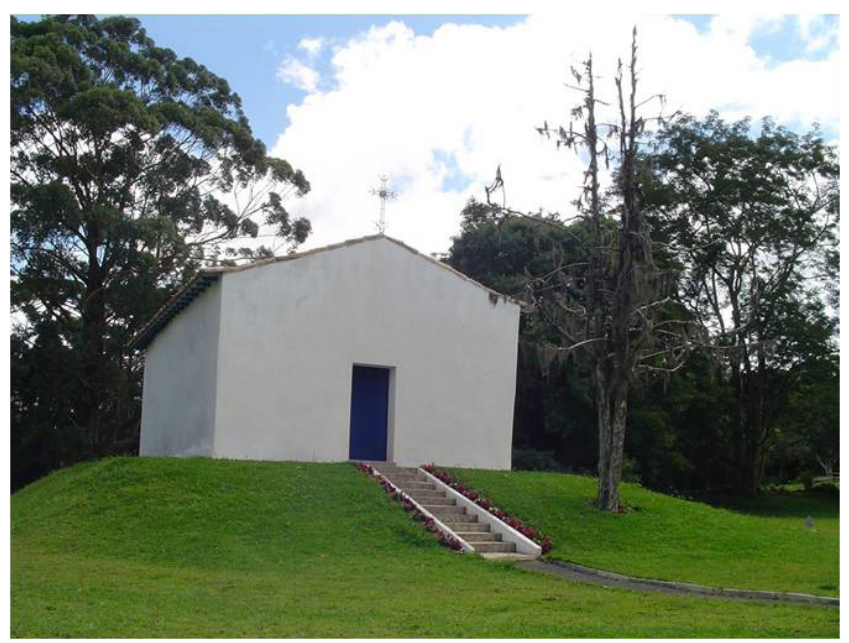

Fonte: SMCT- Ponta Grossa

Os tombamentos não devem ser vistos somente como preservação, mas também como processos de renovação, em que prédios podem tornar-se importantes documentos da história urbana e, por si só, 
potenciais turísticos. O simples instrumento jurídico do tombamento (que não é tão simples assim) não protege totalmente o bem. $\mathrm{O}$ objeto arquitetônico não pode ser visto exclusivamente como objeto visual, por isso estipulou-se neste artigo a concepção de que o bom uso é fator determinante para a persistência da preservação. E esse uso pode também ser turístico. Já afirmava Aloísio Magalhães: “A comunidade é a melhor guardiã de seu patrimônio" (Preservação do Patrimônio Cultural, 1993, p. 22).

Não se deve deixar de lado a questão de que, quando se fala em patrimônio cultural, fala-se fundamentalmente em valores, não se podendo, no entanto, esquecer que os valores são permanentemente imputados a esse patrimônio. Por isso, para falar dos valores culturais (de maneira ampla), deve-se conhecer todo o processo de como o bem foi elaborado, de como ele circulou na sociedade, bem como os atributos a ele referenciados.

Em Ponta Grossa, a prática da preservação de seu patrimônio histórico ainda se vincula à teimosia de poucos que tentam preservar algum referencial. Muitas vezes, a prática preservacionista entra em choque com a ideia de progresso e modernização. Isso pôde ser bem visualizado na cidade, quando a Rede Ferroviária foi parcialmente descaracterizada para ser vendida para a propriedade privada, venda essa justificada por um discurso de modernização e de progresso.

Deve-se entender que a preservação pode se transformar num campo de valorização da qualidade de vida de seus habitantes, da busca de sua cidadania, da preservação do bem cultural, a partir do envolvimento um pouco mais profundo da comunidade com as questões relativas à sua cidade.

\section{Patrimônio Cultural e Turismo: por uma relação necessária}

É importante ainda destacar que a preservação do Patrimônio Cultural não deve se adaptar ao gosto dos turistas; pelo contrário, são os turistas que devem se adaptar à leitura proveniente dos patrimônios. A memória histórica, a identidade, o caráter de uma comunidade - que muitas vezes é referenciada em seu patrimônio - não devem ser banalizados pelo turismo.
O turismo cultural, como é discutido atualmente, não pode somente ser concebido, visto e consumido por intermédio de eventos, festas, grandes espetáculos, mas deve ser pensado e referenciado pela articulação entre preservação, memória e atividade turística.

Sendo assim, o bem que vai ser preservado atualiza-se, identifica-se com o homem, tornando-se parte de seu cotidiano a partir do momento em que por ele pode ser lido. Um trabalho de registro deve ter como tarefa a produção de conhecimento sobre prédios tombados, considerando-os uma fonte de informação, por admitir que a cada novo olhar sobre o objeto, novas informações se revelam. Dessa forma, não se pode mais considerar que o patrimônio seja somente constituído por um mundo de formas e objetos excepcionais, deixando de fora as condições de vida e trabalho de quem os produziu.

Em tal contexto, o acervo do patrimônio cultural, por intermédio do patrimônio edificado, deve ser abordado além de seus valores artísticos e históricos, deve ser visto como produto de fabricação, apreendido por meio da memória do fazer. E para entender a amplitude hoje delegada ao Patrimônio Cultural Urbano, ter-se-ia que conhecer a cidade e a memória histórica e afetiva, a qual, "selecionada pela visão de seus habitantes, desempenha um papel fundamental para o resguardo de sua unidade e continuidade" (CAMPELLO, 1994, p. 24).

Porém, a partir do momento em que os moradores de uma cidade redescobrem seu patrimônio, muitas vezes ajudados pelo olhar do visitante (aquele que vai ao local estudar a comunidade), outra questão se evidencia: a constituição e a defesa do patrimônio possuem sua vertente ideológica, pois “elas são meios pelos quais se dá forma e conteúdo a essas grandes abstrações que são a nacionalidade e a identidade. Desse ponto de vista, não é apenas o que preservar ou não, mas determinar o que defender e como fazê-lo". (ARANTES, 1987, p. 8).

A questão da manutenção das identidades locais está ligada ao processo de globalização. Preservá-las não significa sacralizá-las na comunidade onde se desenvolveram, mas é necessário um alargamento no sentido de dividir com todos aquilo que dá sentido ao seu modo de ser, de ter, de viver, de sentir. Isso porque a troca na atividade turística é permanente e aquilo que diferencia uma comunidade 
de outra, que valoriza o local, pode e deve ser uma ferramenta de atração turística. Não são as diferenças que alimentam as trocas culturais no turismo?

Como afirma Hall (2003, p. 7):

A identidade plenamente unificada, completa, segura e coerente é uma fantasia. Ao invés disso, à medida que os sistemas de significação e representação cultural se multiplicam, somos confrontados por uma multiplicidade desconcertante e cambiante de identidades possíveis, com cada uma das quais poderíamos nos identificar ao menos temporariamente.

Por isso, o planejamento do turismo baseado nas manifestações históricas, sociais e culturais, mas repensadas com imagens e ideias de hoje, pode ser um caminho que leve à busca da reconstrução da identidade local, que muitas vezes se perdeu no mundo de contradições a que o homem esteve (ou está) sujeito nas últimas décadas. Ao pensar e repensar sua história, o homem pode se reencontrar com a cultura que o faz pertencer à comunidade, mesmo que não tenha participado do momento em que determinadas manifestações ocorreram. Ao mesmo tempo, essa reconstrução da identidade pode suscitar lembranças que façam as memórias individuais despertarem e se concretizarem em memórias coletivas, no sentido de dizer "isso é meu, faz parte da minha história". Ao proceder assim, o homem transmitirá ao visitante a essência do lugar onde ele vive, que é diferente de outros lugares.

Uma boa tarefa conjunta para os órgãos de preservação e turismo, é envolver os moradores desde o início, no levantamento do inventário cultural e turístico de suas localidades, proporcionando-lhes um canal de expressão para os vários sentidos que atribuem ao seu patrimônio. (MURTA; GOODEY, 2002, p. 45).

Em decorrência disso, a ideia de Patrimônio Cultural e Turismo aqui proposta é a de, por meio da leitura das realidades patrimoniais, ser possível descobrir aquilo que comumente é chamado de personalidade, identidade. Isso deve acontecer num contexto de permanente valorização do bem cultural, onde a cultura seja entendida como um conjunto de inúmeras interações que o homem cria para si, além das coisas de que ele necessita para sustentar essas relações que estão presentes em seu patrimô- nio. Mas preservar esse patrimônio só se justifica se o homem, frequentemente, continuar explicando essas relações comuns em sua vida, no lugar que escolheu para viver. Segundo Rodrigues (1999, p. 58):

Deter-se no lugar significa abandonar a crença predominante nas soluções pretensamente universais e opor-se a fórmulas externas. Há que se confiar na capacidade e sabedoria das comunidades locais na identificação de seus problemas e na tentativa de soluções originais, com base na sua própria experiência e na de outros grupos similares.

Dever-se-ia possuir um patrimônio reformulado que considerasse seus usos sociais não a partir de uma mera atitude defensiva ou de simples recolhimento, mas com uma visão mais complexa de como a sociedade se apropria de sua história.

A realização da pesquisa ora apresentada evidencia uma preocupação de se pensar o turismo e/ ou atividades turísticas do local para o global, pois, segundo Susana Gastal (2002, p. 9), “o turismo é, talvez, o fenômeno mais globalizado, num mundo de globalizações. A pós-modernidade traz o apagamento das fronteiras e a busca de universalidades. Mas também traz o elogio da diferença". Sendo assim, buscar as especificidades dos patrimônios numa localidade pode contribuir para a realização de inventários e diagnósticos turísticos que muito auxiliarão numa política de planejamento turístico municipal. Por sua vez, os espaços ocupados pelos homens acumulam-se de memórias, de vivências e constituem-se assim em verdadeiros "lugares de memória”. O turismo não pode ser pensado apenas em deslocamentos, mas também em permanências de cultura, por meio da preservação de evidências e elementos que constituem e que criam e recriam a vida da comunidade.

Encerram-se tais reflexões com a seguinte indagação:

A manutenção de identidades culturais e a utilização turística do patrimônio seriam tão antagônicas como uma vez se pensou serem o progresso e a preservação de antigos edifícios? Resta-nos assim um desafio: definir um ponto de equilíbrio entre essas finalidades presentemente atribuídas ao patrimônio cultural, a de ser suporte de identidades e a de ser fonte de divisas. (RODRIGUES, 2001, p. 24). 


\section{Considerações Finais}

Pelo aspecto arquitetônico de beleza, o patrimônio edificado de Ponta Grossa não apresenta um caráter privilegiado, que é comum encontrarmos em outros edifícios tombados no Paraná, assim como também não possui características formais de arquitetura, que são critérios comumente adotados pelos técnicos que trabalham na área de preservação.

Entretanto, os prédios tombados possuem um referencial importante para conhecermos um pouco da história urbana da cidade. Por que construir aqui ou ali? Que critérios foram empregados? O que significou para a cidade a instalação e construção de determinado edifício, num determinado local? Por que se utilizaram determinados elementos decorativos? Como o espaço foi assumido pela comunidade?

Em torno de tais indagações é que deve ser pensado o Patrimônio Cultural para o historiador. Um prédio pode ser estudado como um documento para a história, mas não somente para a história factual. A preservação de um prédio não é mais concebida somente como um cenário para lembrar acontecimentos marcantes. Essas indagações devem ser levadas em conta também pelo turismólogo no processo de planejamento turístico e formatação dos diferentes roteiros turísticos.

Se a história de nosso século, de acordo com o que diz Veyne (1992, p.7), “compreendeu que a sua verdadeira tarefa era a de explicar", as concepções de patrimônio, por sua vez, alargam-se cada vez mais. Poderíamos transpor a afirmação de Veyne sobre a questão de a história possuir condições de explicar, ou não, o patrimônio. O perigo para estudar o patrimônio cultural é que seu estudo parece fácil, mas não o é. A questão do patrimônio cultural, um novo campo sendo explorado como fonte para os historiadores e turismólogos, envolve uma diversidade de elementos que muitas vezes se mostram como grandes abstrações, tais como: cultura, memória, nacionalidade, cidadania e identidade. Que relação pode ser feita entre a questão de preservação de um patrimônio histórico e a preservação da memória? Existe memória histórica?

O historiador e o turismólogo devem, no momento em que entram num campo político como o da preservação ${ }^{5}$, tentar criar uma base firme para aquilo que é patrimônio, dentro de uma sociedade em que os patrimônios já estão concebidos e cristalizados. O patrimônio, isto é, o edifício sofre a ação do tempo e do homem, porém, desde que foi construída, sua estrutura física pode permanecer. $\mathrm{O}$ que muda são as relações sociais que acontecem dentro do espaço e as interpretações que se pode dar ao mesmo.

O conceito de patrimônio foi paulatinamente sendo ampliado. Da noção de patrimônio, vinculada somente a fatos memoráveis da História do Brasil, a construção da memória oficial nacional foi ampliada para questões muito mais abrangentes e, por sua vez, mais complexas.

O debate se dirige para a questão de entender o Patrimônio Histórico e Artístico e o Patrimônio Natural como fazendo parte de um grande conjunto que é o Patrimônio Cultural. O Patrimônio Cultural surge como uma grande gama de diversidades, tais como: Patrimônio Documental, Patrimônio Natural, Patrimônio Museológico e também, arriscaríamos a afirmar, Patrimônio Ideológico (relativo à construção do imaginário).

Essa mudança de conceituação parece lógica, num contexto de crescimento acelerado e, muitas vezes, mal equacionado pelas administrações públicas, que fazem dos centros urbanos grandes aglomerados humanos, atingindo um grau alto de destruição de todas as marcas deixadas pelos seus antecedentes. Perdem-se com isso grandes referenciais, tanto do ponto de vista documental (todo e qualquer registro deixado pelo homem), como do ponto de vista ambiental (destruição dos elementos básicos para a vida). É a tentativa de proteger esses vestígios ameaçados que fez com que se alargassem as noções de patrimônio. Isso tudo a partir do momento em que se consideram como patrimônio todas as manifestações culturais.

Deveríamos possuir um patrimônio reformulado que considere seus usos sociais não a partir de uma mera atitude defensiva ou de simples recolhimento, mas com uma visão mais complexa de como a sociedade se apropria de sua história.

Pode ser que, de posse de um novo referen-

\footnotetext{
${ }^{5}$ Afirmamos a questão de que preservação do patrimônio é uma questão política, no sentido de: quem decide o que preservar? Por que preservar? Ou, ainda, como preservar?
} 
cial, interdisciplinando-se, o historiador, o profissional de turismo e o planejador urbano encontrem um caminho mais efetivo nesse mundo simbólico do patrimônio. No estudo sobre o Patrimônio Cultural (neste caso em particular, o patrimônio edificado), seu desvendamento é 'irresistível' e 'fascinante', fugindo de uma mera interpretação do monumento como arquétipo e estereótipo. "Arquétipo de um passado que se quer salvar. Estereótipo de um futuro que se quer construir" (Maffesoli apud Santos, 1996, p.87).

\section{REFERÊNCIAS:}

ARANTES, A. A. Documentos históricos, documentos de cultura. Revista do Patrimônio Histórico e Artístico Nacional, n. 22, p. 48-55, 1987.

CAMPELLO, G. Patrimônio e cidade; cidade e patrimônio. Revista do Patrimônio Histórico e Artístico Nacional, n. 23, p. 116-125, 1994.

FENELON, D. R. Políticas culturais e patrimônio histórico. O direito à memória: patrimônio histórico e cidadania, São Paulo, Departamento de Patrimônio Histórico, p. 29-33, 1992.

FONTÈS, L. H.; COELHO, M. das G. S.; REIS, A. A. dos; NEVES, M. L. Preservação e desenvolvimento: as duas faces de uma moeda urbana. Revista do patrimônio Histórico e Artístico Nacional, Rio de Janeiro, n. 21, p. 51-55, 1986.

GASTAL, S. (Org.) Turismo, investigação e crítica. São Paulo: Contexto, 2002.

HALL, S. A identidade cultural na pós-modernidade. Tradução de Tomaz Tadeu da Silva. 7 ed. Rio de Janeiro: DP\&A, 2003.

JEUDY, H. P. Memórias do social. Rio de Janeiro: Forense Universitária, 1990.

LEMOS, Carlos A. C. Os (Des)caminhos da preservação. O direito à memória: patrimônio histórico e cidadania, São Paulo, Departamento do Patrimônio Histórico, p.215-222, 1992.

LYRA, C. C. (Coord.). Guia dos bens tombados: Paraná. Rio de Janeiro: Expressão e Cultura, 1984. 202 p.

MENESES, U. T. B. de. O Museu na cidade X A cidade no museu. Revista Brasileira de História, São Paulo, v. 5, n. 8 e 9, p. 197-205, 1984.

MONNET, J. O álibi do patrimônio: crise da cidade, gestão urbana e nostalgia do passado. Revista do Patrimônio
Histórico e Artístico Nacional, n. 24, p. 220-228, 1996.

MURTA, S. M.; GOODEY, B. Interpretação do patrimônio para visitantes: um quadro conceitual. In: Interpretar o patrimônio: um exercício do olhar. Belo Horizonte/ UFMG: Território Brasilis, 2002.

NORA, P. Entre memória e história: a problemática dos lugares. Tradução de Yara Aun Khoury. Revista do Programa de Pós-Graduação em História da PUC/São Paulo. São Paulo: n. 10, dez., p. 7-18, 1993.

PRESERVAÇÃO do Patrimônio Cultural. Instituto Brasileiro do Patrimônio Cultural. $10^{\mathrm{a}}$ Coordenação regional. Curitiba, 1993.

RODRIGUES, M. Preservar e consumir: o patrimônio histórico e o turismo. In: PINSKY, J.; FUNARI, P. P. (Org.). Turismo e Patrimônio Cultural. São Paulo: Contexto, 2001.

SANTOS, Mariza Veloso Mota. Nasce a Academia SPHAN. Revista do Patrimônio Histórico e Artístico Nacional, n 24, p. 77-95, 1996.

SILVA, M. B. S. de R. Preservação na gestão das cidades. Revista do Patrimônio Histórico e Artístico Nacional, n. 24, p. 165-174, 1996.

VEYNE, Paul. Como se escreve a história. 3 ed. Brasília: Editora da Universidade de Brasília, 1982. 198p.

Enviado para publicação: 15/05/2012 Aceito para publicação: 18/06/2012 